TẠP CHÍ KHOA HỌC ĐẠI HỌC TÂN TRÀO

ISSN: $2354-1431$

http://tckh.daihoctantrao.edu.vn/

\title{
Đánh giá chung về chương trình đào tạo ngành sư phạm của Trường Đại học Tân Trào trong xu thế phát triển nguồn nhân lực của tỉnh Tuyên Quang
}

\author{
Nguyễn Đức Hạnh ${ }^{1 *}$, Nguyễn Mỹ Việt $t^{2}$ \\ 1,2 Truòng Đại học Tân Trào, Tuyên Quang \\ *Email:duchanh.xafs@gmail.com
}

\section{Thông tin bài viết}

Ngày nhận bài:

23/5/2019

Ngày duyệt đăng:

$10 / 6 / 2019$

Tù khóa:

sinh viên; nguồn nhân lưc; chuoong trình; đào tạo; tây bắc.

\begin{abstract}
Tóm tắt
Trường Đại học Tân Trào được thành lập năm 2013 theo Quyết định của Thủ tướng chính phủ, là một trường đại học công lập với nhiệm vụ đào tạo, nghiên cứu khoa học và hợp tác quốc tế của tỉnh Tuyên Quang và khu vực miền núi phía Bắc. Trong những năm qua, Trường Đại học Tân Trào đã đào tạo hàng nghìn cán bộ, giáo viên cho tỉnh Tuyên Quang và các tỉnh khác. So sánh chương trình đào tạo ngành giáo dục sư phạm của Trường Đại học Tân Trào trong xu hướng phát triển nguồn nhân lực của tỉnh Tuyên Quang đã đánh giá được vai trò đào tạo nguồn nhân lực phục vụ sự phát triển kinh tế-xã hội của Tuyên Quang nói riêng và vùng Tây Bắc nói chung.
\end{abstract}

\section{Mở đầu}

Ngay từ khi mới thành lập, Trường Đại học Tân Trào đã xác định sứ mạng của nhà trường “Trường Đại học Tân Trào là cơ sở đào tạo đại học, sau đại học, nghiên cứu khoa học, ứng dụng và chuyển giao công nghệ trong các lĩnh vực giáo dục, kinh tế, văn hóa, khoa học kỹ thuật; đóng vai trò nòng cốt trong hệ thống các trường đào tạo chuyên nghiệp của tỉnh Tuyên Quang; sẵn sàng hội nhập quốc tế". Tầm nhìn đến 2030 "Là một trường đại học đào tạo đa ngành chất lượng cao trong hệ thống giáo dục Việt Nam và hội nhập quốc tế hoạt động đảm bảo theo tiêu chuẩn quốc gia và khu vực", phấn đấu trở thành một trong những cơ sở giáo dục đại học có uy tín và chất lượng, góp phần đào tạo nguồn nhân lực chất lượng cao phục vụ sự phát triển kinh tế - xã hội của tỉnh Tuyên Quang và các tỉnh lân cận trong khu vực Tây Bắc.

\section{Nội dung nghiên cứu}

2.1. Mục tiêu của Truờng Đại học Tân Trào với nhiệm vụ đào tạo nhân lục cho ngành su phạm

Trường Đại học Tân Trào đã đặt ra mục tiêu cụ thể đối với đào tạo ngành sư phạm là đào tạo ra các thế hệ giáo viên phát triển toàn diện về các mặt đức dục, trí dục, thể dục, mĩ dục và những kỹ năng hoạt động thực tiễn, làm tốt công tác giáo dục cho học sinh, sinh viên (HSSV) ý thức trách nhiệm và tinh thần say mê, nhiệt tình với sự nghiệp giáo dục miền núi. Nhà trường luôn chú trọng rèn luyện kỹ năng, nghiệp vụ sư phạm và năng lực hoạt động thực tiễn cho người học, trang bị cho HSSV những kiến thức khoa học cơ bản, có tính thực tiễn và kỹ năng thực hành, có kiến thức về văn hoá, văn học nghệ thuật dân tộc. Các thế hệ cán bộ do trường đào tạo đã đáp ứng được những yêu cầu của nhiệm vụ phát triển giáo dục, kinh tế-xã hội ở địa phương Tuyên Quang và khu vực Tây Bắc cũng như cả nước qua mỗi thời kỳ phát triển, có phẩm chất chính trị và trình độ chuyên môn nghiệp vụ tốt, khẳng định thương hiệu của một trường đại học miền núi có uy tín.

\section{2. Đội ngũ giảng viên của Trừ̀ng Đại học Tân} Trào và các hoạt động phục vụ nhiệm vụ đào tạo nhân lục cho ngành sư phạm giai đoạn 2006-2016

Đội ngũ cán bộ, giảng viên của nhà trường có phẩm chất chính trị, có năng lực chuyên môn nghiệp vụ vững vàng, kỹ năng nghề nghiệp thành thạo để đáp ứng các điều kiện cần thiết về chuyên môn nghiệp vụ, thực hiện công tác giảng dạy và nghiên cứu khoa học. Đặc biệt từ năm 2010 đến năm 2016, đội ngũ giảng viên của nhà trường đã có sự chuyển đổi theo hướng tích cực cả về 
số lượng và chất lượng, số giảng viên có trình độ tiến sĩ, thạc sĩ được tăng lên qua mỗi năm học, chất lượng đội ngũ giảng viên được nâng lên, đây là một trong những yếu tố quan trọng để nhà trường thực hiện công tác đào tạo sinh viên có hiệu quả. Số lượng giáo viên hiện có về cơ bản đáp ứng được nhiệm vụ đào tạo của trường. Cơ cấu đội ngũ giáo viên hợp lý với các chuyên ngành đào tạo. Số lượng giảng viên có học vị tiến sỹ, thạc sỹ chiếm tỉ lệ xấp xỉ $100 \%$ trong số giảng viên trực tiếp giảng dạy.

Giai đoạn từ năm 2006-2016, nhà trường có nhiều giảng viên tham gia thực hiện các đề tài nghiên cứu khoa học các cấp, các đề tài có giá trị khoa học và thực tiễn gắn liền với sự phát triển kinh tế-xã hội của địa phương và khu vực, viết nhiều giáo trình, sách chuyên khảo, tài liệu tham khảo phục vụ công tác chuyên môn, có nhiều bài báo khoa học đăng trên các tạp chí khoa học có uy tín trong và ngoài nước, nhiều sản phẩm khoa học được công bố trên các tạp chí quốc tế xếp trong danh mục ISI, Scopus, tạp chí khoa học Trường Đại học Tân Trào có mã số quốc tế ISSN và được tính điểm theo Quyết định của Hội đồng chức danh giáo sư nhà nước, nhiều sản phẩm khoa học công nghệ cao đã được chuyển giao, ứng dụng vào sản xuất và cung cấp dịch vụ đáp ứng cho nhu cầu của xã hội.

Hoạt động đảm bảo chất lượng giáo dục được triển khai trong toàn trường, hướng tới phục vụ cộng đồng đã làm cho chất lượng dạy và học trong nhà trường được nâng lên, giảng viên thực hiện nghiêm túc quy chế chuyên môn, giữ vững kỷ cương, nề nếp, từng bước hình thành văn hoá chất lượng giáo dục trong nhà trường. Trong từng năm học, nhà trường thực hiện công khai cam kết chất lượng giáo dục và chất lượng giáo dục thực tế. Công khai cam kết chất lượng giáo dục đối với các bậc đào tạo hệ chính quy gồm: công khai về điều kiện tuyển sinh: Thực hiện công tác tuyển sinh theo đúng quy định của Bộ Giáo dục và Đào tạo, chất lượng đầu vào được đảm bảo, phù hợp với đặc thù của trường đóng trên địa bàn miền núi; Công khai chương trình đào tạo toàn khoá, ban hành chuẩn năng lực nghề nghiệp đầu ra cho các ngành đào tạo. Nhà trường đã bổ sung, điều chỉnh và công bố chuẩn đầu ra các ngành đào tạo trên cơ sở kinh nghiệm thực tiễn đào tạo và điều kiện đặc thù của trường để đảm bảo chuẩn đầu ra có tính khoa học và thực hiện được trên thực tế. Thực hiện cam kết các điều kiện mà sinh viên được thụ hưởng khi vào học tại trường theo từng chuyên ngành đào tạo, công khai về điều kiện cơ sở vật chất, đội ngũ giảng viên, các hoạt động hỗ trợ người học, yêu cầu cần đạt được về kiến thức, kỹ năng, thái độ đối với sinh viên và vị trí làm việc sau khi tốt nghiệp ở các trình độ.

Giai đoạn 2006-2016, Nhà trường đã đa dạng hoá các loại hình đào tạo để đáp ứng nhu cầu của xã hội, từ đào tạo một loại hình duy nhất là đào tạo giáo viên cho các trường trung học cơ sở của 02 tỉnh Tuyên Quang, Hà Giang và một số tỉnh trong khu vực Tây Bắc. Đến nay nhà trường đã tuyển sinh viên từ nhiều tỉnh thành trong cả nước, mở thêm nhiều ngành đào tạo đại học, cao đẳng chính quy; hệ đào tạo vừa làm vừa học, đào tạo liên thông, các ngành trong và ngoài sư phạm. Bồi dưỡng hàng trăm cán bộ quản lý giáo dục các cấp, cấp hàng ngàn chứng chỉ chức danh nghề nghiệp, tin học, ngoại ngữ, cung cấp dịch vụ đào tạo, bồi dưỡng nguồn nhân lực cho các cơ sở giáo dục và các ngành nghề khác trên địa bàn tỉnh Tuyên Quang và các tỉnh khu vực Tây Bắc cũng như cả nước.

\section{3. Đánh giá chung về Chuơng trình đào tạo ngành sư phạm của Truờng Đại học Tân Trào}

Chương trình đào tạo ngành sư phạm của trường được xây dựng dựa trên chương trình khung của Bộ Giáo dục và Đào tạo ban hành. Chương trình đào tạo có mục tiêu rõ ràng, cụ thể, đáp ứng yêu cầu về kiến thức, kỹ năng của từng trình độ đào tạo, đáp ứng được nhu cầu của thị trường lao động trong và ngoài tỉnh, thường xuyên rà soát, bổ sung, điều chỉnh chương trình giáo dục nhằm có được chương trình giáo dục tiên tiến, hiện đại phù hợp với sự phát triển chung của cả nước. Ngoài ra, nhà trường còn chú ý tới nhu cầu đào tạo nguồn nhân lực của tỉnh Tuyên Quang, các tỉnh lân cận và khu vực Tây Bắc trong quá trình xây dựng chương trình.

Đề cương chi tiết của các ngành đào tạo được giao cho các giảng viên chính hoặc các giảng viên có kinh nghiệm xây dựng và được các giảng viên của từng bộ môn trong trường tham gia đóng góp, chỉnh sửa. Hội đồng Khoa học đào tạo nghiệm thu, trình Hiệu trưởng phê duyệt và định kỳ 2 năm một lần chỉnh sửa, bổ sung. Chương trình các ngành đào tạo được ban hành và phổ biến đến tất cả các khoa, giảng viên, HSSV bằng văn bản và lưu trữ tại văn phòng các khoa, trung tâm, phòng ĐT-NCKH, bộ phận Đảm bảo chất lượng giáo dục. Ngoài ra, chương trình và kế hoạch đào tạo từng khoá học còn được thông báo trực tiếp cho tất cả sinh viên trong "Tuần sinh hoạt công dân - HSSV" và được giáo viên chủ nhiệm công bố trên lớp vào đầu mỗi học kỳ. 


\subsubsection{Chuoong trình đào tạo chuyên ngành giáo dục mầm non}

Giáo dục mầm non là cấp học đầu tiên trong hệ thống giáo dục quốc dân, đặt nền móng cho sự phát triển về thể chất, nhận thức, tình cảm xã hội và thẩm mỹ cho trẻ em. Giáo dục mầm non thực hiện việc nuôi dưỡng, chăm sóc giáo dục trẻ em với mục tiêu là giúp trẻ em phát triển về thể chất, tình cảm, trí tuệ, thẩm mỹ, hình thành những yếu tố đầu tiên của nhân cách, chuẩn bị cho trẻ em vào lớp một. Những kỹ năng mà trẻ được tiếp thu qua chương trình chăm sóc giáo dục mầm non sẽ là nền tảng cho việc học tập và thành công sau này của trẻ. Do vậy, phát triển giáo dục mầm non, tăng cường khả năng sẵn sàng đi học cho trẻ là yếu tố quan trọng trong việc phát triển nguồn nhân lực chất lượng cao cho đất nước.

Những năm đầu đời đóng vai trò vô cùng quan trọng trong việc hình thành nhân cách và phát triển năng lực của trẻ, bởi tuy trẻ bẩm sinh đã có khả năng tiếp thu học tập, não bộ đã được lập trình để tiếp nhận các thông tin cảm quan và sử dụng để hình thành hiểu biết và giao tiếp với thế giới, nhưng thiên hướng học tập của trẻ có thể bị hạn chế bởi nhiều yếu tố như thể chất, nhận thức và tình cảm xã hội. Việc được hưởng sự chăm sóc và phát triển tốt từ lứa tuổi trẻ thơ sẽ góp phần vững chắc cho sự phát triển trong tương lai của trẻ. Giáo dục mầm non sẽ chuẩn bị cho trẻ những kỹ năng như tự lập, sự kiềm chế, khả năng diễn đạt rõ ràng, đồng thời tạo hứng thú cho trẻ đối với việc đến trường tiểu học để bước vào giai đoạn giáo dục phổ thông. Với tầm quan trọng đặc biệt của giáo dục mầm non trong quá trình giáo dục hình thành trí tuệ, sức khỏe và nhân cách của con người, đồng thời để đạt được mục tiêu của giáo dục mầm non thì đội ngũ giáo viên mầm non đóng vai trò rất quan trọng quyết định việc học tập và phát triển của trẻ. Giáo viên được đào tạo tốt sẽ có nhiều tương tác với trẻ tích cực hơn, nhanh nhạy hơn, thích ứng hơn, cung cấp những trải nghiệm về phát triển nhận thức và ngôn ngữ phong phú hơn để giúp trẻ phát triển toàn diện.

Chương trình đào tạo ngành giáo dục mầm non được xây dựng với mục tiêu giúp người học có được những kiến thức cốt lõi và kỹ năng cơ bản trong công tác chăm sóc và giáo dục trẻ mầm non, đáp ứng yêu cầu xã hội đối với sự phát triển giáo dục mầm non. Người học có thể đảm nhiệm được công việc của giáo viên mầm non trong các loại hình cơ sở giáo dục mầm non và có thể tham gia công tác quản lý thuộc lĩnh vực mầm non và các lĩnh vực khác. Nội dung chương trình đào tạo ngành sư phạm mầm non gồm các học phần chung, các học phần cơ sở, học phần chuyên môn, học phần tự chọn và thực tập tốt nghiệp. Chương trình cung cấp cho người học hệ thống kiến thức cơ bản về tâm lý trẻ lứa tuổi mầm non, kế hoạch chăm sóc, kỹ năng nghiệp vụ cơ bản để đảm bảo thực hiện tốt công việc của người giáo viên mầm non, đáp ứng được các yêu cầu của nghề nghiệp đặc thù, có khả năng tham gia vào hoạt động chăm sóc giáo dục trẻ tại các cơ sở giáo dục mầm non công lập hoặc tư thục.

\subsubsection{Chuoong trình đào tạo chuyên ngành giáo dục} tiểu học

Chương trình đào tạo ngành giáo dục tiểu học cung cấp kiến thức cơ bản về các môn học theo quy định bậc tiểu học, có khả năng hệ thống hóa kiến thức trong cả cấp học để nâng cao hiệu quả giảng dạy đối với các môn học ở bậc tiểu học. Có kiến thức về tâm lý học sư phạm, tâm lý học lứa tuổi và giáo dục tiểu học, vận dụng kiến thức vào hoạt động giáo dục và giảng dạy phù hợp với đối tượng học sinh tiểu học. Có kỹ năng sư phạm thành thạo để tổ chức và thực hiện các hoạt động dạy học nhằm phát huy tính năng động sáng tạo của học sinh. Sau khi ra trường sinh viên dạy được các môn học ở bậc tiểu học, có khả năng đảm nhận các công việc trong ngành giáo dục và các ngành có liên quan phù hợp với chuyên ngành đã được đào tạo.

Chất lượng của riêng chương trình giáo dục tiểu học được đánh giá qua chất lượng giáo viên. Chất lượng giáo viên tiểu học được xác định bởi các tiêu chí cơ bản về phẩm chất chính trị, đạo đức, lối sống, kiến thức, kỹ năng sư phạm đáp ứng mục tiêu của giáo dục tiểu học theo quy định của Bộ Giáo dục và Đào tạo, gồm 03 lĩnh vực, 15 yêu cầu với 60 tiêu chí. Trên cơ sở các quy định của Bộ, Trường Cao đẳng Sư phạm Tuyên Quang (nay là Trường Đại học Tân Trào) đã ban hành quy định chuẩn đầu ra đối với các hệ đào tạo cao đẳng, trung cấp sư phạm ngành tiểu học, để thực hiện điều tra, khảo sát, nhà trường đã tích hợp, lồng ghép, cụ thể hóa để xây dựng hệ thống các tiêu chí trong Phiếu điều tra giáo viên tiểu học do trường đào tạo từ năm 2006 đến năm 2015 hiện đang công tác tại các tỉnh Tuyên Quang, Lào Cai, Hà Giang, Điện Biên, tập trung vào 3 vấn đề chủ yếu: (1) Sự thích ứng với môi trường công tác; (2) Khả năng phát triển và nâng cao trình độ chuyên môn, nghiệp vụ; (3) Việc đáp ứng nhu cầu của ngành giáo dục, của địa phương, của xã hội. Các vấn đề được khảo sát theo 05 nhóm với 30 tiêu chí: (1) Nhóm tiêu chí I: 
Phẩm chất chính trị, đạo đức, lối sống; (2) Nhóm tiêu chí II: Hoạt động nghề nghiệp; (3) Nhóm tiêu chí III: Ý thức, tinh thần trách nhiệm trong công việc; (4) Nhóm tiêu chí IV: Khả năng phát triển nghề nghiệp; (5) Nhóm tiêu chí $\mathrm{V}$ : Khả năng đáp ứng nhu cầu sử dụng nguồn nhân lực tại cơ sở giáo dục, địa phương.

Sau khảo sát, đánh giá 5 nhóm tiêu chí đối với giáo viên tiểu học cho thấy kết quả đạt được phản ánh phù hợp với chuẩn đầu ra của trường và chất lượng giáo viên tiểu học theo đánh giá của cơ sở giáo dục, so sánh với các tiêu chí của Chuẩn nghề nghiệp giáo viên tiểu học thì đội ngũ giáo viên tiểu học được khảo sát tại các trường tiểu học trên địa bàn 04 tỉnh cơ bản đạt Chuẩn quy định.

2.3.3. Chưong trình đào tạo chuyên ngành giáo dục trung hoc co sở (THCS)

Chương trình giáo dục hệ đào tạo giáo viên trung học cơ sở được nhà trường xây dựng theo Quyết định số 15/2004/QĐ-BGD\&ĐT ngày 10/6/2004 của Bộ trưởng Bộ Giáo dục và Đào tạo về việc ban hành Bộ chương trình khung giáo dục đại học khối ngành cao đẳng sư phạm, với mục tiêu giúp người học có đủ năng lực chuyên môn và nghiệp vụ đảm bảo được những yêu cầu đổi mới mục tiêu, nội dung, phương pháp, hình thức tổ chức dạy học, kiểm tra đánh giá kết quả giáo dục đáp ứng yêu cầu phát triển giáo dục trung học cơ sở về quy mô, chất lượng, hiệu quả, phục vụ sự nghiệp công nghiệp hóa, hiện đại hóa đất nước; có tiềm lực để không ngừng hoàn thiện trình độ đào tạo ban đầu, vươn lên đáp ứng những yêu cầu mới. Sinh viên tốt nghiệp cao đẳng sư phạm hệ đào tạo giáo viên trung học cơ sở có thể dạy được hai môn học trong kế hoạch dạy học ở trường THCS theo chuyên ngành được đào tạo, có thể làm công tác chủ nhiệm lớp, tổ chức các hoạt động giáo dục ngoài giờ lên lớp..., có những phẩm chất cơ bản của người giáo viên, yêu nghề, có ý thức trách nhiệm xã hội, đạo đức, tác phong người giáo viên.

Nội dung chương trình đào tạo giáo viên trung học cơ sở gồm các học phần thuộc khối kiến thức giáo dục đại cương chung cho khối ngành cao đẳng sư phạm và riêng cho từng ngành đào tạo; các học phần thuộc khối kiến thức giáo dục chuyên nghiệp gồm kiến thức nghiệp vụ sư phạm chung cho khối ngành, học phần khối kiến thức chuyên môn trong chương trình đào tạo song ngành, ngành chính và ngành phụ, các học phần tự chọn và thực tập tốt nghiệp. Chương trình được rà soát, bổ sung, điều chính hàng năm theo mục tiêu khi hoàn thành chương trình đào tạo và tốt nghiệp, người học có đủ khả năng để hoàn thành tốt công việc sau khi ra trường đó là hiểu và vận dụng được những kiến thức cơ bản về khoa học giáo dục để có thể tổ chức giảng dạy, kiểm tra đánh giá kết quả, biết vận dụng những kiến thức cơ bản và phương pháp dạy học các môn học, các hoạt động giáo dục ở nhà trường THCS. Với những kiến thức và kỹ năng đạt được sau khóa đào tạo tại Trường Đại học Tân Trào, sinh viên đã đạt chuẩn năng lực đầu ra theo quy định, có tác phong công nghiệp, có trách nhiệm nghề nghiệp, có tinh thần sáng tạo, luôn cập nhật thông tin để nâng cao chất lượng giáo dục.

2.3.4. Đánh giá chung về thực hiện nhiệm vụ đào tạo ngành su phạm

Trường Đại học Tân Trào là cơ sở đào tạo nguồn nhân lực giáo viên chủ yếu cho tỉnh Tuyên Quang, trong quá trình đào tạo, nhà trường luôn xác định tầm quan trọng của chương trình đào tạo, với xu thế xã hội luôn đổi mới và phát triển thì việc đổi mới chương trình là cần thiết vì có đổi mới nội dung chương trình, đổi mới phương pháp dạy học và hình thức tổ chức dạy học thì người học mới cập nhật được những vấn đề mới, những yêu cầu đạt chuẩn được đặt ra với ngành nghề được đào tạo. Sau khi kết thúc mỗi khóa học, nhà trường tổ chức rà soát, bổ sung và điều chỉnh chương trình đào tạo để đảm bảo chương trình đào tạo mang tính hiện đại, thiết thực, phù hợp với thực tiễn, sinh viên ra trường có kỹ năng nghề nghiệp, tự tin, vững vàng và sẽ được sự tiếp nhận của các nhà tuyển dụng, đồng thời khẳng định được thương hiệu của nhà trường về chất lượng nguồn nhân lực do nhà trường đào tạo. Nhà trường nhận thức rõ chương trình đào tạo là một trong những điều kiện tiên quyết, góp phần quyết định chất lượng đào tạo, vì vậy đổi mới chương trình giáo dục phù hợp với thực tiễn và nhu cầu xã hội sẽ giúp cho người học có năng lực thực hành nghề nghiệp tốt hơn, dễ tiếp cận với công việc ở các trường mầm non, tiểu học và THCS.

Một nhiệm vụ quan trọng của quá trình đào tạo là việc rèn luyện nghiệp vụ sư phạm (NVSP) cho sinh viên nhằm mục đích hình thành ở người học những phẩm chất và kỹ năng cần thiết đáp ứng yêu cầu hoạt động thực tiễn giáo dục ở trường mầm non, tiểu học và THCS. Quá trình này đòi hỏi phải thường xuyên tổ chức cho sinh viên thâm nhập thực tế, kiến tập các hoạt động mẫu, thực hành, thực tập các kỹ năng sư phạm. Rèn luyện NVSP thường xuyên sẽ giúp sinh viên đến thực tập sư phạm tại các trường mầm non, tiểu học và THCS một cách tự tin và chủ động hơn. Trong những 
năm qua, Trường Đại học Tân Trào đã chỉ đạo thực hiện tốt công tác thực tập sư phạm cho sinh viên, nhà trường đã tổ chức cho sinh viên đến thực tập sư phạm tại các trường mầm non, tiểu học và THCS thuộc địa bàn thành phố Tuyên Quang, huyện Yên Sơn, Hàm Yên, Chiêm Hóa, Sơn Dương, lựa chọn các trường có quy mô giáo viên và học sinh phù hợp, cơ sở vật chất đảm bảo, đội ngũ giáo viên có kinh nghiệm trong công tác quản lý và có năng lực về chuyên môn nghiệp vụ để hướng dẫn thực tập cho sinh viên. Gắn kết chặt chẽ giữa các trường mầm non, tiểu học và $\mathrm{THCS}$ và cơ sở đào tạo giáo viên trong tổ chức dạy và học không những giúp sinh viên định hướng nghề nghiệp mà còn biết vận dụng lý luận vào thực tiễn và quan trọng hơn là sinh viên được thực hành, thực tập, rèn luyện nghiệp vụ sư phạm.

Với chương trình được rà soát, bổ sung, điều chỉnh hàng năm theo mục tiêu khi hoàn thành chương trình đào tạo và tốt nghiệp, người học có đủ khả năng để hoàn thành tốt công việc sau khi ra trường đó là hiểu và vận dụng được những kiến thức cơ bản về khoa học giáo dục để có thể tổ chức giảng dạy, kiểm tra đánh giá kết quả và quản lý quá trình giáo dục ở các cấp học; Biết vận dụng những kiến thức cơ sở và phương pháp dạy học các môn học, các hoạt động giáo dục ở chương trình bậc học mầm non, phổ thông; Vận dụng kiến thức cơ bản về chăm sóc sức khỏe trẻ lứa tuổi mầm non để lập kế hoạch, tổ chức các hình thức chăm sóc sức khỏe cho trẻ; Tổ chức các hình thức dạy học bộ môn, biết vận dụng những kiến thức cơ bản và phương pháp dạy học các môn học, các hoạt động giáo dục. Với những kiến thức và kỹ năng đạt được sau khóa đào tạo tại Trường Đại học Tân Trào, sinh viên đạt chuẩn năng lực đầu ra theo quy định, người giáo viên tương lai có tác phong công nghiệp, có trách nhiệm nghề nghiệp, yêu nghề, có tinh thần sáng tạo, luôn cập nhật thông tin để nâng cao chất lượng chăm sóc giáo dục trẻ trong các trường mầm non và nâng cao chất lượng giáo dục toàn diện trong các trường tiểu học và THCS.

\section{Kết luận}

Trường Đại học Tân Trào, Tuyên Quang trong những năm qua đã đào tạo được hàng vạn giáo viên và cán bộ quản lý giáo dục các cấp và cán bộ các ngành khác phục vụ cho sự nghiệp phát triển kinh tế - xã hội của tỉnh Tuyên Quang, khu vực Tây Bắc và cả nước. Hàng năm, học sinh sinh viên tốt nghiệp ra trường được tiếp nhận làm việc tại các cơ sở giáo dục với tỷ lệ cao, cung cấp thêm nguồn nhân lực cho ngành giáo dục và các ngành khác cả về số lượng và chất lượng. Hầu hết sinh viên được đào tạo tại trường, đến nay đã trưởng thành về mọi mặt, có trình độ chuyên môn vững vàng, có năng lực trong công tác quản lý, nhiều người đã trở thành cán bộ quản lý tại các cơ sở giáo dục và các cơ sở khác. So sánh số lượng sinh viên đã được nhà trường đào tạo giai đoạn 2006-2015 và số lượng cán bộ, công chức, viên chức của tỉnh Tuyên Quang, số lượng sinh viên tốt nghiệp công tác tại các tỉnh khác trong khu vực đã khẳng định vị trí và vai trò to lớn cũng như hiệu quả đào tạo của nhà trường trong sự phát triển kinh tế xã hội của tỉnh Tuyên Quang, khu vực Tây Bắc và cả nước.

\section{Lò̀i cảm ơn:}

Đại diện nhóm tác giả (Nguyễn Đức Hạnh) xin cảm ơn sự hỗ trợ của các đồng nghiệp cùng tham gia nghiên cứu, các cán bộ phòng ban thuộc Trường Đại học Tân Trào và sự hỗ trợ kinh phí từ đề tài nghiên cứu khoa học cấp Bộ của Trường Đại học Tân Trào, mã số B2017-TQU-01.

\section{TÀI LIỆU THAM KHẢO}

[1]. Chiến lược phát triển Trường Đại học Tân Trào giai đoạn 2018-2025, định hướng đến năm 2030 (2018).

[2]. "Đánh giá hiệu quả đào tạo của Trường Đại học Tân Trào đối với sự phát triển kinh tế-xã hội của tỉnh Tuyên Quang và vùng Tây Bắc và giải pháp phát triển nhà trường đến năm 2030", Đề tài nghiên cứu khoa học cấp Bộ 2017. Mã số B2017-TQU-01. 


\section{General assessment of Tan Trao University's pedagogical training program in the trend of human resource development of Tuyen Quang province}

Nguyen Duc Hanh, Nguyen My Viet

\section{Article info}

Recieved:

23/5/2019

Accepted:

$10 / 6 / 2019$

Keywords:

students; $\quad$ human

resources; programe;

training; northwest.

\begin{abstract}
The University of Tan Trao has established at 2013 by decided of Prime Minister of Viet Nam goverment, is a public university with the task are training, scientific research and international cooperation of the Tuyen Quang province and region of the Northwest mountains. Over the years, the University of Tan Trao awarded annually and provides training for Tuyen Quang province and other provinces in the country serving thousands of staff for education and training sector, manager and other sectors. Compare the program training of the pedagogical education in the Tan Trao University in the trend develop the human resource of Tuyen Quang province, has affirmed location and a great role in the task of training human resources sevices for socio-economic development of Tuyen Quang province in particular and the Northwest region and the country in general of the University of Tan Trao.
\end{abstract}

